\title{
Modernizm Ölçeğinde Bir Şiir Haritası: İmkânsız Özerklik
} ARŞ. GÖR. GIZZEM ECE GÖNÜL**

"Bizi olanaklı kılanlar neyi olanaklı kılmakta olduklarım bilemezlerdi ve dolayısıyla eserlerinin birer araç oluşturduğu amaçları betimleyemezlerdi. Ama biz bunu yapabiliriz." Richard Rorty

Imkânsız Özerklik üst başlığına sahip eser, Yalçın Armağan'ın 2007 yılında Bilkent Üniversitesi Ekonomi ve Sosyal Bilimler Enstitüsü Türk Edebiyatı Bölümünde tamamladığı Türk Şiirinde Modernizm isimli doktora tezinin genişletilmiş hâlidir. Alt başlıkta tezin ismini de barındıran kitabın ana sorunsalı Türkiye modernleşmesinin Türk şiiri üzerinden nasıl okunabileceğidir. Çalışma bu sebeple sosyoloji ve edebiyat paslaşmasında bir metodoloji de sunar.

Armağan, kitabın "Ön Söz" ve "Giriş" bölümlerinde çalışmanın yönteminin ters kronolojiye dayandığını, asıl amacının modernizmin izlerini İkinci Yeni şiiri üzerinden sürmek olduğunu ancak bu şiirin bir dirençle karşılaştığını tespit edip zamanda geriye

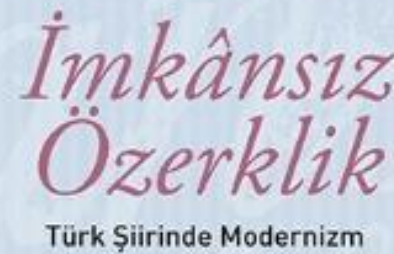

(2)

YALCIIN ARMAG̈AN dönme ihtiyacı duyduğunu belirtir. Bu da yazarı ilk olarak Garip şiirine, devamında Cumhuriyet'in inkılap şiirine, Ziya Gökalp’a ve onun da öncesine 1850'lere, Tanzimat'a değin götürür. Böylece söz konusu direnci yaratanın, Türkiye modernleşmesinin erken dönemlerinde inşa edilen estetik tepkiler olduğu iddia edilir. Peki uzun bir sürece yakından bakmayı hedefleyen Armağan bunca ismi, eseri nasıl bir yöntemle işleyecektir? Sorunun cevabını doğrudan veren yazar, "edebiyat kurumu"ndaki dönüşümleri esas aldığını; şiirde etki alanı açan, kırılma yaratan, dönüm noktası sayılabilecek şair veya şiir akımları odağında bir kroki çizdiğini ifade eder. Bahsi geçen noktanın tespiti tartışmalı olsa da araştırmacı, okuru ikna edebilmiş, Türk şiirinin değişen çizgisini şablonlaştırabilmiş, her şeyden önemlisi de nedenleştirebilmiştir. Bunu yaparken Armağan, modernizm ölçeğini elden bırakmayıp şiirde bu kavrama bağlı olarak gelişen estetik tepkilerin güzergâhını saptamıştır.

\footnotetext{
${ }^{* *}$ Muğla Sıtkı Koçman Üniversitesi Edebiyat Fakültesi Türk Dili ve Edebiyatı Böl. gizemecegonul@gmail.com
} 
Araştırmacının tarihselliğin peşine terselmeyle düşüp bunu epizodik anlatımla sunması özgün bir yöntem denemesi olarak karşımıza çıkar. Buna Armağan'ın konuya bir adım geriden bakmaya çalışan üslubu da eklemlenince eser, Bertolt Brecht'le can alan epik tiyatro kavramının âdeta izdüşümüdür. Yazarın söz konusu üslubu, tıpkı bu tiyatro türündeki gibi "yabancılaştırma" unsuru hâline gelmiş ve Türk şiirinin bir çeşit kurgu olduğu düşüncesini uyandırarak kurgusallığın nasıllığı üzerinde durulmuştur. Elbette bu farkındalığı yakalamada "sonradan gelmek" önemlidir. Türk şiirinin izlediği rota, yoldayken görülemezdi bunun için ancak alınan yola uzaktan ve "sonradan" bakmak gerekirdi.

Üç bölümden meydana gelen araştırmanın ilk bölümü teorik zemini oluşturur. Bu bölümde modernizmin neliğinden, modernleşmeyle beraber sanatın aldığ sanatların bir kolu olan edebiyatın, özelde de Türk edebiyatının, bu kavramla karşılaşmasının doğurduklarından bahsedilir. Modernliğin ilk kez Batı'da deneyimlendiğini söyleyen yazar, Türkiye' de bu modelle kurulan modernliğin yanlışlığına değinir ve edebiyat tarihi açısından açtığı oyukların kısa bir panoramasını çizer. Ahmet Haşim'e yöneltilen "sembolist" yakıştırmasının yalnızca Haşim ile Batılı sembolistler arasında yapılan kuru bir karşılaştırmanın sonucu olduğunu söyleyip Fransa'da sembolizmin karşılık geldiği dünya görüşünün yok sayıldığı üzerinde durur. Türk edebiyatını, Batı etkisinde gelişen "taklit edebiyat" olarak görmekten kaçınılması gerektiğini vurgulayan Armağan, söz konusu modele yaklaşıldığında "yabancılık"; modelden uzaklaşıldığında ise "yavanlık" hissinin yaşandığının altını Nurdan Gürbilek ve Orhan Koçak'ın ifadeleriyle çizdikten sonra "yabancılık" ile "yavanlık" arasındaki bu gerilimde Türk modernleşmesinin konumlandığını iddia eder. Belirtmekte fayda var ki Armağan, salt bir modernizm tanımı yapma peşinde değildir. Hatta mutlak surette tanımlamanın yapılamayacağını, modernizmi tanımlama gayretinin dahi modernist bir karakter taşıdığını belirtip bu “indirgemeci heves"ten kaçınılmasını gerekçeleriyle birlikte gösterir. Öyle ki kavramı tanımlamanın zorluğu farklı eleştirmenlerden, teorisyenlerden yapılan alıntılarla da perçinlenir. Yazarın bu kavrama yer vermedeki amacı onu işlevsel hâle getirmek ve modernleşmenin sonuçlarının edebiyata, şiire nasıl yansıdığını göstermektir. Böylece modernizm ve edebiyat birlikteliğinden modernist yapıtın özellikleri irdelenmeye başlanır ta ki kitabın temel problematiği olan "estetik özerklik" kavramina gelinceye dek.

Kant'ın "aklını kendin kullanma cesaretini göster" ilkesinin, Weber'in "aklın yapılarının özerkleşmesi" savının ve Wagner'in "özgünlük ve özerklik" iddialarının işaret ettiği modernlik projesi, Armağan'ın “özerkleşme” yi irdelemesine, edebiyattaki özerkleşme sürecine de "estetik özerklik" parametresini getirmesine kapı aralar. Mucidinin Fredric Jameson olduğu kavram, modernist eserin yapı taşı olmakla beraber "kendi kendine yeten", “amacı kendinde olan”, “özgöndergesel” ya da "özdönüşümsel” olma iddialarını taşır. Şiir 
dilinin kendine yeterlik savı ise Armağan'ın bu türü inceleme altına almasına neden olur. Modern öncesi dünyada şairin belirli araçlarla şiir yazdığına, gösterenlerin de gösterilenlerin de sınırlı bir dairede yer almaları sebebiyle şiirin anlaşılabilirlik için özel birikime sahip olmadığına değinen yazar, sonraki dönemlerde şiirin kendi araçlarını geliştirdiğini böylece modern edebiyatta dilin kendini kolay ele vermeyen göstergeler içerdiğini ve bu yüzden modern şiirin zor anlamlandığını belirtir.

İkinci bölümde teorinin uygulama alanına gelinir ve Türk şiirinin modernleşme odağındaki estetik parametreleri ortaya konulup yakından incelenir. Bunlar "Divan edebiyatının icadı”, “halk edebiyatının keşfi”" ve "özerklik karşıtlığı” şeklinde tasnif edilir. Adı geçen değişkenler aynı zamanda "edebiyat kurumu”nun da şekillendiricileridir. Peter Bürger'in "sanat kurumu" kavramından ödünçlenen deyiş, "edebî eserlerin üretimini, alımlanmasını etkileyen baskın düşünceler" (22) karşılığında kullanılmıştır. Armağan, kanon tartışmalarının da bu başlık altına dâhil edilmesinin yerinde olduğunu belirterek yeni bir kavramın doğumunu üstlenir. Esere göre modernleşmenin ilk evreleri 1850'lerin ikinci yarısıdır ve bu yıllarda "yeni edebiyat kurumu" nu inşa eden metinler Şinasi, Namık Kemal, Ziya Paşa'ya aittir. Yazarın bu isimleri tespit etmesinin sebebi antolojilerde, edebiyat tarihlerinde ismi geçen edebiyatçıların ürünlerinin "seçme metinler" olarak yer almasıdır. Söz konusu sanatçılar "ilk modernler" olarak anılır ve onların, kendinden öncekileri reddederek "geleneksizleşme"yi tercih ettikleri Armağan tarafından saptanır. Bu dönemde Batı' daki hazır model aracılığıyla edebiyatın nasıl olacağından önce taşımaması gereken özelliklere değiniliyor ve bu konu etrafında pek çok makale kaleme alınıyor. Araştırmacının belirttiği üzere bir yandan model karşısında "geç kalmışlık", "çocuk" olma hissi duyularak tarihin gerisine düşülüyor diğer yandan eski edebiyat "ölü" nitelemesiyle tarih dışına itiliyor. Bu noktada tarihsel bir bağ kuran Armağan aynı tepkinin 1911 sonrasında da Cumhuriyet yıllarında da kullanıldığını söyler ve Nurullah Ataç'ın 1936'daki “Bizim dün edebiyatımız yoktu" söylemini bu üç dönemin mottosu ilan eder. Çalışmanın modeli bu örnekte de görülebileceği gibi yatay bir düzlemde inşa edilmiş ve eserde yer yer ileri-geri gidilerek ilmekli bir yapı yaratılmıştır. Bu durum, Armağan'ın da ifade ettiği üzere modernizmi de özerklik kavramını da "tarihsel anlatı" formuna dönüştürmüştür. Böylece geçmişin, gecikmişliğin sorumlusu görüldüğü her tarihte geleneksel olanın değerini kaybedip halk edebiyatının yerli öz olarak kabul edildiğini söyleyen yazar, Tanzimat'ın sade dil savunucularının da hececi şairlerin de aynı evrelerden geçtiğini dile getirir.

Geleneğe yönelen eleştirilerin neliğini araştıran Armağan, 1911 yılında Divan edebiyatının "gayri millî" ve "halktan kopuk olması" nedenleriyle eleştirildiğini tespit ettikten sonra 1950'li yıllarda bu harekete "biçimci" olduğu için karşı olunduğunu söyler. Buradan hareketle 50'li yıllarda edebiyatta istenmeyen niteliğin "biçimcilik" olduğu çıkarımı 
yapılır ve eleştiri yönünde toplumdaki sorunların etkili olduğu gösterilir. Benzer şekilde 1945 yılında edebî eserlerde "köylüden bahsedilmemesi" eleştirilirken öncesinde böyle bir tenkit yönünün olmaması sosyal sorunlarla ilgilidir. Yalçın Armağan, böylece edebiyata sosyolojik bir pencere de açıyor, içeriğin eleştirisini yapıyor ve eleştiri alanını genişletiyor. Divan edebiyatına getirilen rasyonel olmadığı, hayale fazlaca yer verdiği eleştirisi de dünyayı modern biçimde kavramanın bir sonucu olarak görülüyor ve neticede "modernleşmenin sonuçlarından biri olarak görülen özünü yitirme korkusunu bastırmak için" (20) halk edebiyatına sığınılıyor.

"Halk edebiyatının keşfi" parametresini "Modernizmi Hece'lemek" başlığ1 altında inceleyen Armağan, hececi şiiri köklü bir dönüşümün nedeni olarak tespit eder. 1911'den itibaren "Beş Hececiler" ve 1930'lu yıllarda "Bağımsız Hececiler"in önderlik ettiği bu şiir, araştırmacı tarafından tarihsel açıdan önemli görülür. Bu dönemde halkın anlayacağı dil esas kabul edilir ve aruzla yazmaya devam edenlere yönelik ağır eleştiriler kaleme alınır. Bu, Armağan'a göre estetikten ziyade siyasi bir tavırdır çünkü aruzdan kastedilen Osmanlı kültürüdür. Görüldüğü üzere buraya kadar anlatılan mesele, Türk şiirinin özerklikten ne denli uzak olduğudur. Osmanlı şiirinin belirli kurallarının olması onu özerklikten alıkoyarken Recaizade Mahmut Ekrem, Abdülhak Hamit Tarhan estetik özerkliğe yönelen ilk isimler olarak tespit edilse de devamlarının olmayışı nedeniyle şiiri bu kavramla birleştirememiştir. Tevfik Fikret, şiir dilinden bahsetmesiyle özerkliğin göstergesi olarak yorumlanacaksa da dönüşüm yaşatamaz. Ahmet Haşim'in "her şeyden evvel şunu itiraf edelim ki şiirde manadan ne kast edildiğini bilmiyoruz" sözüyle bir çeşit estetik özerklik anlayışını savunduğu söylense de şiire yeni bir dil sunmadığı, araştırma düzeyinde kaldığı gerekçesiyle şair dışarıda bırakılır. Millı̂ edebiyat da şiiri tek bir merkezde konumlandırma ihtiyacı gütmesi nedeniyle özerklikten payını alamaz.

Armağan'ın şiir çizelgesi Garip şiirini gösterdiğinde bu akım ve Cumhuriyet'in 1930'lu yıllarda inşa etmek istediği kültür arasında denklik kurulur. İkisinde de "makbul"lüğün önemsendiği, "tektip"lik üzerinde durulduğu söylenir. Garip şiirinin halk dilini kullanma ve eskiyi reddetme bağlamları düşünüldüğünde "makbul bir şiir" olduğunu belirten yazar bu akımı, "beklenen ama beklenen biçimde gelmeyen şiir" (97) sözleriyle özetler. Kısa zamanda yaygınlık kazanmasıyla beklenen şiir olduğunu ancak metin düzleminde aykırılığı barındırmasıyla, şairaneliği yıkma arzusuyla, sanat kurumuna karşı duruşuyla beklenen şekilde gelmediğini iddia eden Armağan'ın, Garip'in etki alanı konusunda yanıldığı söylenebilir. Çünkü araştırmacının bahsettiği şekilde Garip şiiri tepkisiz karşılanan, kolayca benimsenen bir şiir olmamıştır. Yazara "Türkiye modernleşmesinin kamusal modeli ile Garip şiirinin uyum içinde olduğu" (114) tespitini yaptıran muhtemelen sosyo-politik bakış açısıdır ancak diğer taraftan söz konusu şiire olan itirazlar da hatırlanmalıdır. 
Çalışmanın son bölümünde estetik parametrelerin nihai adımı olan "özerklik karşıtlı̆̆g" meselesine İkinci Yeni şiiri üzerinden değinilir ki başta da belirtildiği gibi her ne kadar eserde bu dönem en az hacme sahip olsa da temel mesele onun odağında kurulur. İkinci Yeni şiiri gerek kendine has şiir diliyle gerek "şiir anayasaya aykırıdır" söylemiyle özerk bir edebî yapıtta aranan "amacı kendinde olma”, “özdüşünsel”, “özgöndergesel” kertelere uygun görülür. Yalçın Armağan İkinci Yeni şiirinin maddi temellerini arar ve bu şiirin “Türkiye'nin 'özgül' koşullarından beslendiğini” (127), kaynağının “Türkiye toplumunun yaşadığı krizler [olduğunu]" (124), "Batı'yı tanıyıp Türkiye'ye uygun pratik yarattığını" (128) tespit eder. Aynı zamanda Armağan sosyalist şairler zor dönemler yaşarken, kovuşturmalar geçirirken İkinci Yeni şairlerinin anılan tarihte bu olaylardan uzak durmasını dilde yaptıklarını dönüşüme bağlar. "Anlaşılır" olmayan İkinci Yeni şairleri bu bağlamda iktidarın ufkunun dışında kalırken okurun ya da edebiyat kurumunun da beklenti ufku dışında kalmıştır. Çünkü yazara göre bu şairler hikâyeyi değil, "kelimeler arasında kurulacak 'şiirsel yük'ü önemserler" (131) ve böylece anlam geri plana itilip özerk şiir dilinin yolu açılır. Modern edebî yapıtlarda dilin çok katmanlı olduğu daha önce de belirtilmişti, buna uygun şekilde İkinci Yeni'de de "nesnelerin uzlaşımsal dille anlatılmaması" (148), "sanat gerçeğinin esas alınması" (149), "dilsel sapmalar ve metaforlar" (150) özerk yapının izleri olarak görülür. Ancak bu yapı, şiddetli bir dirençle karşılanır ve özerklik tam da bina edileceği sırada darp edilmeye başlanır. $\mathrm{Bu}$ son bölümle birlikte uvertür sayılabilecek İmkânsız Özerklik başlıklandırmasının tercih nedeni açığa çıkar. Türk şiirinin izlediği tarihsel süreçte araştırmacının tanımladığı şekilde estetik özerklik kaygısının güdülmediği, kaygının oluşum alanı bulsa da kısıtlandığı ve bu sebeple "imkânsızlaştığı” yorumu yapılır.

Yalçın Armağan, Türkiye'de modernleşmeye bağlı olarak gelişen tepkileri üç başlık altında toplayarak bunlar üzerinden arzuların, kaygıların okunmasını; onanıp onanmayan unsurlardan hareketle edebiyat kurumunun dönüşüm halesinin gözlemlenmesini; modernleşme sürecinin çoklu bir bakışla daha iyi kavranabileceğini olanaklı kılar. Araştırmacı, genelde edebiyat, özelde de şiir ve sosyoloji perspektifinden modernleşme deneyimini incelemiş ve birden fazla modernleşme süreci tespit edilerek bu meselenin aydınlanabileceğini göstermiştir. Çalışma "ileri sürüyorum”, "iddia ediyorum", "sorguluyorum" gibi berrak ifadeleri barındırmasıyla amacını bilen bir zihnin ürünü olduğu hissini uyandırır. Armağan, soruları vasıtasıyla tartışmalı bir üslubu yakalayabildiği gibi bu soruların muhtemel cevaplarını da verebilmiştir. Âdeta neden-sonuç zinciriyle ilerleyen çalışma, dönemler arası paslaşmaları da boşlukları da yakalayıp lehine değerlendirebilmiştir. Ancak yazar her ne kadar çalışmayı tarihsel devirlere ayırsa da eser, sonuçtan girişe gelerek kurgulandığ için fazlaca tekrara ev sahipliği yapar. İkinci Yeni şiirine dair tespitleri yazarın çıkış noktası olduğu için Tanzimat dönemi anlatılırken bir anda Cumhuriyet'e sıçrayışlar 
görülür. Elbette ki bu, tarihsel anlatıyı kurma açısından olumlu bir özellik kabul edilebilir ancak aynı meseleler Cumhuriyet şiiri başlığında da anlatılınca tekrar kaçınılmaz hâle gelir. Öte yandan yazarın niyeti en başta da belirtildiği gibi İkinci Yeni’nin bir dirençle karşılaştığı kabulü üzerine kurulduğu ve bu direncin gösterimi olduğu için benzer meseleler çalışmanın ilk satırlarından itibaren ele alınır. Eserin yöntemine dönük yapılabilecek bir eleştiri de metnin kanıtlarının birbirine denk biçimde kurgulanmadığıdır. Şöyle ki Ahmet Haşim anlatılırken yalnızca şairin sözlerine yer verilir; oysa İkinci Yeni şiirine gelindiğinde şiir dahi çözümlenir. Hâl böyle olunca metin içi tutarsızlık göze çarpar ve Armağan'ın inandırıcılığına gölge düşer. Ahmet Haşim'de yazarın niyeti esas alınırken diğerinde eserin niyeti de devreye girer. İkinci Yeni bahsindeki hızlı geçişler; ön kabullü, verili dil de buna eklenince durum perçinlenir. Bir başka ikili durum ise Armağan'ın eser boyunca "Türkçe eleştiri”, "Türkçe edebiyat", “Türkçe şiir" kavramlarını tercih ederken kitabın kapağında "Türk şiiri" adlandırmasının kullanılmasıdır. Ne var ki Yalçın Armağan’ın özgün bir bakış yakaladığı muhakkak olan bu çalışma modernizmin, modernleşmenin edebiyat-sosyoloji hattında okunarak hem Türk şiirinin evrelerini kavramada hem de tarihsel anlatıyı çözümlemede etkili, işlevsel bir yöntem sunar. 